\title{
Trees Outside Forests (Trees on Farmlands): Assessment of Farmers Perception in Gaya Local Government Area, Kano State, Nigeria
}

Dantani Abdulmalik ${ }^{1 *}$, Babangida Abubakar ${ }^{3}$, Mustapha Abdulkarim Sani ${ }^{2}$, Ridwan Bunza Mukhtar ${ }^{1}$, Muhammed Alimu Gupa ${ }^{4}$ and Ahmed Bello ${ }^{5}$

${ }^{1}$ Department of Forestry and Wildlife Management, Bayero University, P.M.B. 3011, Kano, Nigeria

${ }^{2}$ Department of Agronomy, Bayero University, P.M.B. 3011, Kano, Nigeria

${ }^{3}$ Department of Forestry and Environment, Usmanu Danfodiyo University, P.M.B. 2346, Sokoto, Nigeria

${ }^{4}$ Department of Forestry and Wildlife, University of Maiduguri, P.M.B. 1069, Borno State, Nigeria

${ }^{5}$ Department of Forestry and Wildlife, Federal University Dutse, Jigawa State Nigeria

\section{Article History \\ Received: 07.11 .2020 \\ Accepted: 17.11 .2020 \\ Published: 22.11.2020 \\ Journal homepage: http://www.easpublisher.com}

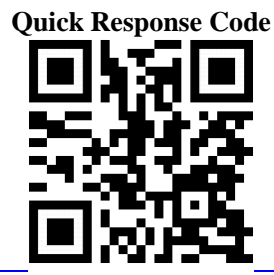

Abstract: The study was carried out in order to assess the perception of Farmers on Trees outside Forest (Trees on Farmlands) in Gaya Local Government Area of Kano State. Stratified random sampling was used, the study area was partitioned in to eleven wards from which three wards were selected at random; selection of villages was done proportionally from the selected wards. One hundred and twenty (120) questionnaires were administered to farmers. Data collection was done through direct contact with farmers. Descriptive and inferential statistics were used in analyzing the data. Charts, frequency distribution and percentages were used to preset demographic information while chi-square test of association was used to check relationship between socioeconomic characteristics and tree planting on farm lands. The results obtained on demography showed that, majority of the respondents fall between 48-58 years, about 91\% are male and $9 \%$ are female, $94 \%$ are farmers and $92 \%$ are married. Chi-square result revealed no significant association between demography and Trees outside forest except with age and household size which showed significant relationship. (Older people plant more trees on the farmlands compare to the younger ones and also large household plant more trees than the smaller household).

Keywords: Perception, Farmers, Trees Outside Forest, Sampling and Chi-Square.

Copyright (C) 2020 The Author(s): This is an open-access article distributed under the terms of the Creative Commons Attribution 4.0 International License (CC BY-NC 4.0) which permits unrestricted use, distribution, and reproduction in any medium for non-commercial use provided the original author and source are credited.

\section{INTRODUCTION}

Lack of appropriate forest management and utilization, land tenure policy and lack of compatible forest legislations could result to deforestation. However, Population growth and the associated expansion of agricultural lands is the primary cause of present-day deforestation [1,2]. Globally, substantial efforts are put into the monitoring of forest resources [3] and there are good reasons for this due to the multitude of ecosystem services provided by forests. However, tree resources that grow outside forests typically are not taken into account by forest monitoring programmes even though they provide similar services as forest trees. Such tree resources are summarised with the term trees outside forests (TOF). Furthermore, the relevance of TOF for human livelihood, general environmental conditions, and biodiversity was emphasized $[4,5]$. Trees outside forest (TOF) are said to be trees that have attained $10 \mathrm{~cm}$ or more diameters at breast height present on lands not regarded as forests [6]. The TOF plays a vital ecological role, social and economic roles providing goods and ecosystem services to the people $[7,5,8]$. They basically include woodlands, shrubberies, urban trees, scattered trees, farm trees and many more. People have managed TOF in the form of agroforestry and urban plantings for longer term $[9,10]$ for instance in the form of agroforestry systems [11]. However, TOF have mostly been left out in most forest statistics, assessments and policies because they are typically split among the various categories of agroforestry, urban and rural forestry [12]. But the interest in TOF and its assessments have emerged basically because the protection and enhancement of tree cover in non-forest land will be needed to complement the protection of forest areas [13]. Trees are typically the largest components of aboveground biomass in terrestrial ecosystem $[14,15]$ and regardless of their location they are important for carbon storage. Likewise, reporting obligations from international conventions has also made it necessary for conduct TOF assessment particularly the United Nations Framework Convention on Climate Change (UNFCCC) and United Nations Convention on Biological Diversity (UN-CBD) have urged on keeping up-to- date information on tree 
resources within and outside forests [15]. Likewise, the Kyoto protocol has particularly, emphasized on the inclusion of TOF in national forest monitoring systems [16].

Farm trees provide fodder, food, farm-yardmanure (FYM) and fuelwood (4Fs), high value crops, coffee, teas, edibles, medicinal plants. Food and income from agroforestry and naturally growing trees on farmlands and urban lands constitute an important component on individual household food supply [17]. These trees support the daily livelihood of people in both direct and indirect way. The cultural benefits of TOF extend to neighborhoods and environmental benefits may accrue to whole urban area, like the reduction of urban heat island effect [18]. TOF provide various ecosystem services such as control over soil erosion, nutrient and water cycling, biodiversity conservation or pest control $[19,20]$. The $80 \%$ of the requirements of the wood-based industries are met from TOFs [21]. TOF also play an important role in both the sequestration and storage of carbon [22] considering as mitigation alternatives. In the context of Climate Change, the assessment of TOF has become much more relevant as TOF make an important contribution to climate change mitigation but are not systematically accounted for in either global carbon budgets or national carbon accounting. Globally, it has been estimated that about 33 giga tones of biomass carbon is stored in trees on agricultural land using coarse spatial resolution satellite data [7]. On a finer scale, the data of TOF is rare and availability varies typically across fragmented institutions and stakeholder [16]. But there are exceptions where systematic study has been conducted such as the National Forest Monitoring and Assessment (NFMA) program by FAO [16] and some of the country's own assessment such as China's national forest inventory [23].

Trees influence rainfall through evapotranspiration. About $10-20 \%$ of the rain falling onto the forest never reaches the ground; the rain drops are intercepted by the tree canopy and evaporated back into the atmosphere. This is experienced in most tropical forests. Forest canopy and the understory vegetation protect the soil surface against the abrasive action of rain drops, thereby minimizing erosion and surface runoff. The roots of trees grow deeper in the soil than arable crops. These roots absorb water at a deeper soil depth which is transpired to the atmosphere, forming clouds that in turn release water in the form of rainfall [24]. Tree crops are often used in shelterbelts, particularly in arid regions to minimize wind speed, and combat desert encroachment. Trees provide a barrier against the destructive action of heavy windstorm; acting as windbreak for annual crops. Binding action of the roots, if left undisturbed, the ground beneath tree crops becomes covered with a layer of debris called forest litter (comprising dead leaves, twigs, branches, and $\log$ s at various stages of decomposition). The litter and humus layers that accumulate in the long run absorb moisture and further modulate the infiltration rate of the underlying soil. The heavy canopy of plantations is effective in maintaining ideal humidity and microclimate in the immediate and adjoining environments, while the dense root volume explores the soil for nutrients and water thereby minimizing leaching and runoff losses; thus, reducing pollution of underground and surface water [24]. The roots of trees are estimated to be 1.5-3 times stronger than the roots of grassy plants of the same diameter, and a tree possesses thousands of leaves and hundreds of kilometers of roots with hundreds of thousands of root tips; all contributing to the binding action on soil particles. When land is devoid of vegetation, the organic matter which decomposes gradually will be exposed to high temperature which leads to rapid depletion and resultant $\mathrm{CO}_{2}$ emission that increase global warming. Because plantation crops are heavy feeders, they are capable of absorbing large amounts of substances introduced to the soil either through fertilizer application and waste management or atmospheric impurities washed down with torrential rainstorms. Trees and other plantation crops take up nutrients from the soil and incorporate them in their biomass. These nutrients are only released back to the soil when the leaves of the trees fall or when the plants die and decay. Part of the tree biomass is eaten by various soil animals (including insects and earthworms), and their excreta return nutrients to the soil. In the soil, a huge number of soil microorganisms are involved in the decomposition of organic materials which makes nutrients available to plant roots [24].

\section{Materials AND Methods Study area}

This study was conducted in Gaya local Government Area of Kano State Nigeria. It is located on latitude $11^{\circ} 12^{\prime} \mathrm{N}$ and longitude $9^{\circ} 12^{\prime} \mathrm{E}$. It is bordered in the North by Ajingi Local Government, to the West by Wudil Local Government, to the South by Albasu Local Government, and to the East by Dutse Local Government area of Jigawa State. Gaya Town is the headquarter of Gaya Local Government, established in 1976, and it is located in the southern part of Kano State with distance of $65 \mathrm{Km}$ from Kano City. Gaya has an estimated population of about 201,016 [25].

\section{Soil and Vegetation}

The soil types are mainly sandy, loamy and brown to reddish brown in color; however, alluvial soils are found around rivers which make the soil highly productive. The natural vegetation of the study area falls under Sudan Savannah type [26]. It is composed of variety of tree species scattered over an expanse of grassland. The trees are usually characterized by broad canopies and they are hardly taller than 2 meters. Grasses hardly grow more than 1.5 meters at maturity except in favored spots. There are also some thorny shrubs and medium trees in the drier interfluves and the 
rocky areas or dissected terrain. The types of trees mostly found in the study area include Adansonia digitata, (baobab), Acacia species, Mahogany, Azaradica indica and Eucalyptus species etc.

\section{Weather and Climate}

The precipitation occurs during the summer month starting mostly from May and ends in October. The beginning and length of rainfall vary from year to year. The highest amount of rainfall is characterized by strong wind, thunder and lightning. The showers are intense and last for short period. The average rainfall in a normal year is about $864.1 \mathrm{~mm}$. The dominance of this wind system in this region marked the period of dry season, which is partly dry and hot and the dry and cold. The dry hot season period is between March and May.

\section{Sampling procedure and Sampling size}

Reconnaissance survey will be carried out to make the researcher familiarize himself with the study area; determine the demography and economic activities in the study area with interest on farmers. Gaya Local Government constitute eleven wards (Balan, Gaya, Garmarya, Gamoji, Gaya Arewa, Gaya Kudu, Kademi,, Wudiyawa, Shagogo, Maimakawa ,Kazurawa) three of these districts were selected at random through balloting, proportional sampling was used in selecting villages.

Table-1: Sampling Procedure used in the study Area

\begin{tabular}{|l|c|c|c|}
\hline Wards & Number of Villages & Sampled villages & N0. of respondents \\
\hline Balan & 11 & 3 & 30 \\
\hline Shagogo & 13 & 4 & 40 \\
\hline Kademi & 17 & 5 & 50 \\
\hline Total & 41 & 12 & 120 \\
\hline
\end{tabular}

\section{Data Collection}

Primary and Secondary information were used for this study. One hundred and Twenty questionnaires were administered, retrieved and analyzed while the secondary information was obtained from relevant literatures, text book, journals, past projects and internet.

\section{DATA ANALYSis}

The data obtained were screened and organized, analyzed using descriptive and inferential statistics to achieve the stated objectives. The statistical tool to be used include percentages, pie-chart, frequency distribution and chi-square to test association between socioeconomic characteristics and the dependent variables (deforestation and trees on agricultural land). SPSS version16 was used for the analysis.

\section{RESUltS AND DisCUSSION}

Socioeconomics characteristics of the Respondents

Figure 1 below showed the age distribution of the respondents. It was revealed that, majority of the respondents $43(35.8 \%)$ were between the age ranges 48 58 years, while those between $37-47$ years were representing 39(32.5\%). Also, 29 respondents (24.2\%) are 59 and above, while 9 respondents (7.5\%) fall between 15-25 years old.

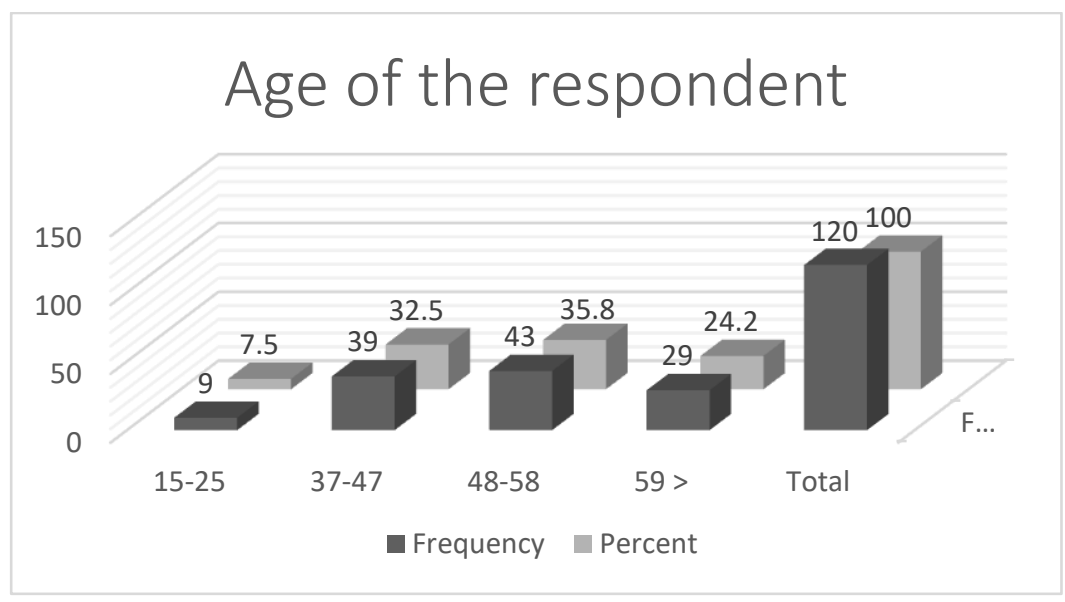

Fig-1: Age of the respondents

\section{Gender of the Respondents}

Figure 2 below showed the distribution of respondents by gender. It indicated that out of the 120 respondents $109(91 \%)$ were males and $11(9 \%)$ were females. This revealed that there are more male farmers than female in the study area. 


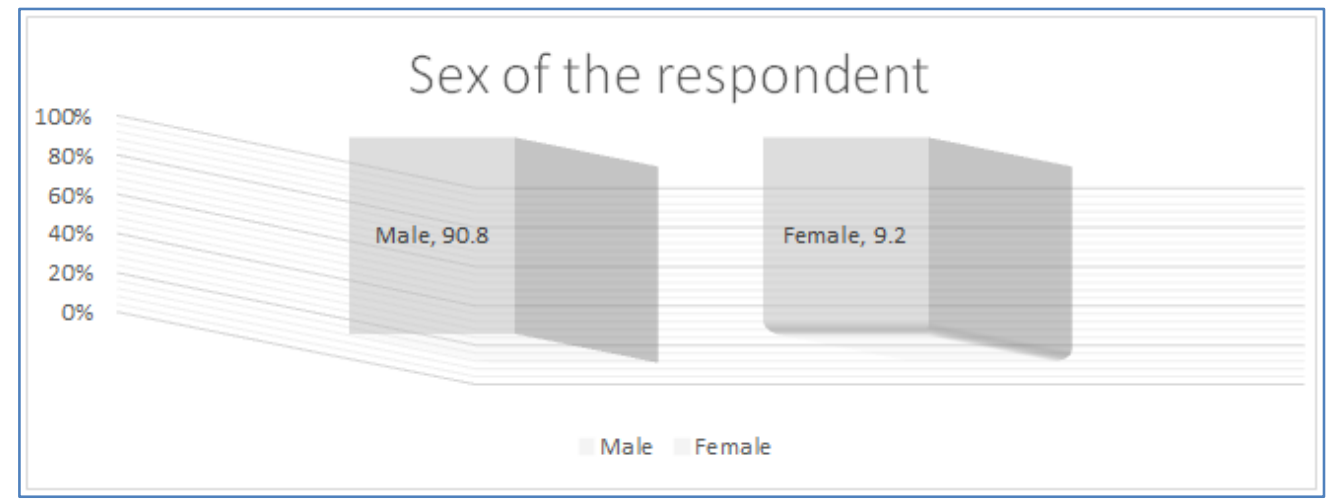

Fig-2: Gender of the respondents

\section{Marital status of the respondents}

The result from the research shows that 94

$(78.3 \%)$ of the respondent are married and $6(5 \%)$ are single, while $4(3.3 \%)$ are divorced and $16(13.3 \%)$ are widows. From this we can deduce that, the majority of the respondents are married.

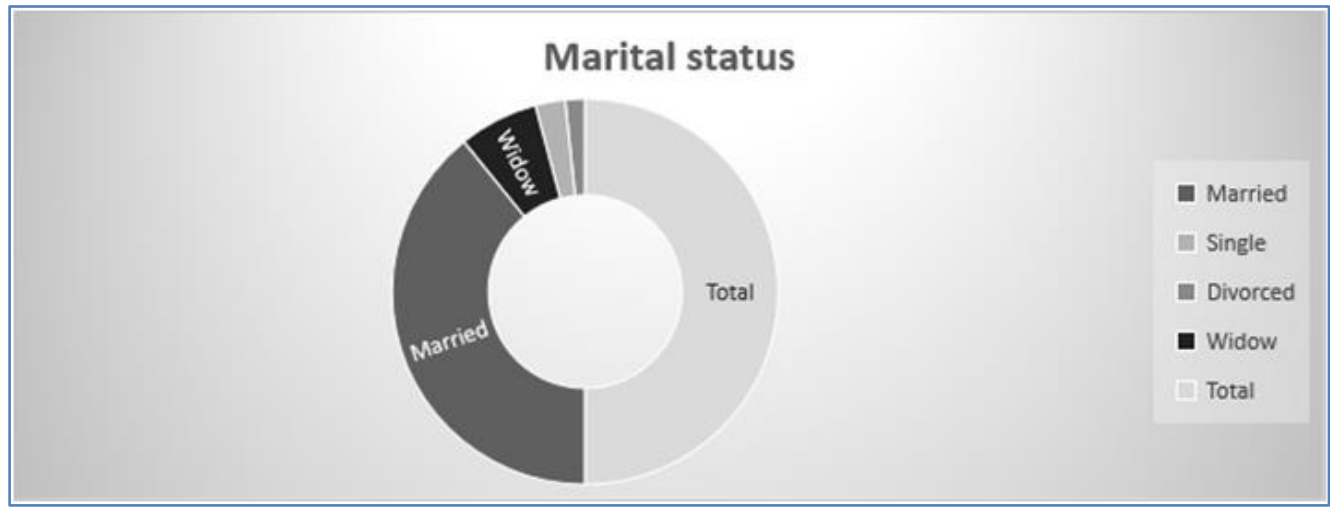

Fig-3: Marital status of the respondents

\section{Household size}

A household unit comprises the household head, wife or wives, children and other dependents living with them. From the results in the table below shows that, there are more respondents with household size ranges from 4-7, having a frequency of 49 and 39.2 percent.

Table-2: Household size

\begin{tabular}{|l|l|l|}
\hline Household & Frequency & Percentage (\%) \\
\hline $0-3$ & 9 & 7.5 \\
\hline $4-7$ & 49 & 39.2 \\
\hline $8-11$ & 31 & 25.8 \\
\hline$>12$ & 33 & 27.5 \\
\hline Total & $\mathbf{1 2 0}$ & $\mathbf{1 0 0 . \%}$ \\
\hline
\end{tabular}

\section{Educational status of the respondent}

Table 3 showed educational status of the respondents, 61(50.8\%) non-formal education (Qur'anic literacy), 54 (45\%) of the respondents have attended secondary schools, $3(2.5 \%)$ of the respondents completed primary education, finally $3(1.7 \%)$ of the respondent attended tertiary institutions. This indicated that majority of respondent (farmers) are informally educated.

Table-3: Educational status of the respondents

\begin{tabular}{|l|l|l|}
\hline Educational status & Frequency & percentage \\
\hline Primary & 3 & 2.5 \\
\hline Secondary & 54 & 45.0 \\
\hline Tertiary & 2 & 1.7 \\
\hline Non-formal & 61 & 50.8 \\
\hline Total & $\mathbf{1 2 0}$ & $\mathbf{1 0 0}$ \\
\hline
\end{tabular}

\section{Occupation of the respondents}

Figure below showed the occupation of the respondents, frequency and percentage distributions are as follows, farming, business, civil servant with $113(94.2 \%), 3(2.5 \%)$ and $4(3.3 \%)$ frequency and percentage respectively. 


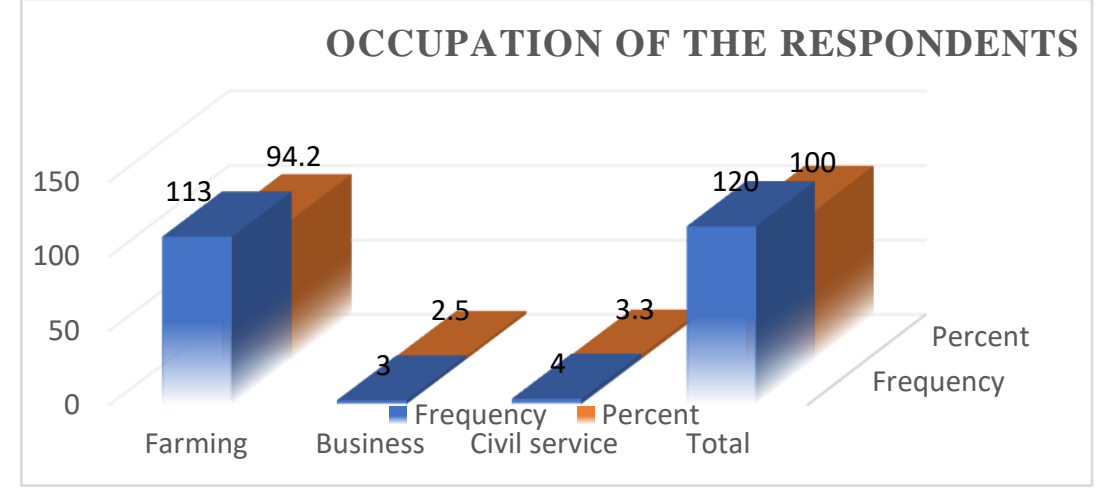

Fig-4: Occupation of the respondents

\section{Types of Farming practice}

The types of farming practice in the locality are basically three, which are mixed farming, mixed cropping and agroforestry. $70 \%$ of the sampled population are practicing mixed farming, $21.7 \%$ Mixed cropping and the lowest value was obtained from agroforestry with $8.3 \%$, this shows that majority of the farmers in the study area do not plant trees which are very important in conserving nutrients, moisture and farmland protection from wind and water erosion.

Table-4: Farming practices of the respondents

\begin{tabular}{|l|c|c|}
\hline Farming practice & Frequency & Percentage \\
\hline Mixed Farming & 84 & 70.0 \\
\hline Mixed cropping & 26 & 21.7 \\
\hline Agroforestry & 10 & 8.3 \\
\hline Total & $\mathbf{1 2 0}$ & $\mathbf{1 0 0 . 0}$ \\
\hline
\end{tabular}

\section{Importance of Trees on Farmlands}

From the result in table 5 below, 54.2 percent opined that trees on farmlands improve soil fertility with only $5 \%$ said trees prevent desert encroachment.
Table-5: Trees outside Forests (Trees on Farmlands)

\begin{tabular}{|l|l|l|}
\hline Benefits & frequency & Percentage \\
\hline Serves as wind breaks & 31 & 25.8 \\
\hline Prevent erosion & 18 & 15.0 \\
\hline Improve soil fertility & 65 & 54.2 \\
\hline Prevent desertification & 6 & 5.0 \\
\hline Total & $\mathbf{1 2 0}$ & $\mathbf{1 0 0}$ \\
\hline
\end{tabular}

\section{Perception of farmers on trees outside forests TOF}

This presents Chi-square analysis of the respondents, in analyzing and establishing relationships between socio-economic characteristics of the respondents and trees outside forests the following were obtained: No significant association (relationship) between demographic information and trees outside forest (TOF) with the exception of age and household size, which revealed significant relationship. From this we can say that age and household size have positive relationship with tree on farmlands.

\begin{tabular}{|c|c|c|c|}
\hline Chi-square result (relationship between socio economic characteristics and trees outside forests) \\
\hline Variables & $\mathbf{X}^{\mathbf{2}}$ & $\mathbf{D f}$ & P-value \\
\hline age & 45.070 & 6 & $0.000^{*}$ \\
\hline sex & 1.99 & 2 & 0.368 \\
\hline Marital status & 7.363 & 6 & 0.289 \\
\hline House hold size & 37.160 & 6 & $0.000^{*}$ \\
\hline Educational status & 11.269 & 6 & 0.080 \\
\hline occupation & 1.227 & 4 & 0.874 \\
\hline
\end{tabular}

*Significant $(\mathrm{P}<0.05)$

\section{CONCLUSION AND}

\section{RECOMMENDATION}

\section{Conclusion}

Conclusively, there were more male than the female farmers in the study area and most of the respondents have no formal education. There was no significant association between demography and Trees outside forest except with age and household size which showed significant relationship. (Older people plant more trees on the farmlands compare to the younger ones and also large household plant more trees than the smaller household).

From the above results obtained during this research, I strongly recommend the followings:

- Government should provide a vastly expanded funding mechanism, such as competitive grants to enable farmer's plant and monitor economic tree species on their farmlands as one of the mechanisms in combating climate change and achieving sustainable agriculture. 
- Extension services are strongly needed to enlighten farmers to adopt planting of trees and arable crops on the same land (Agroforestry) to achieve sustainability between agriculture and environment.
- There should be a specific program for women in agriculture so as have more women in farming enterprise as the sector is dominated by men.

\begin{tabular}{|l|l|l|l|}
\hline \multicolumn{5}{|l|}{ Common Tree Species Found in the Study Area } \\
\hline S/n & Family name & Botanical name & Local names \\
\hline 1 & Fabaceae & Tamarindus indica & Tsamiya \\
\hline 2 & Fabaceae & Parkia biglobosa & Dorawa \\
\hline 3 & Fabaceae & Piliostigma reticulatum & Kalgo \\
\hline 4 & Malvaceae & Adansonia digitate & Kuka \\
\hline 5 & Fabaceae & Faidherbia albida & Gawo \\
\hline 6 & Meliaceae & Khaya senegalensis & Madaci \\
\hline 7 & Ebenaceae & Diospyrus mesipiliformis & Kanya \\
\hline 8 & Fabaceae & Acacia sieberrians & Fara-kaya \\
\hline 9 & Sapotaceae & Butyrospernum parkii & Kadanya \\
\hline 10 & Fabaceae & Acacia nicotica & Bagaruwa \\
\hline 11 & Anacacardiaceae & Mangifera indica & Mangoro \\
\hline 12 & Meliaceae & Azadirachta indica & Darbejiya \\
\hline
\end{tabular}

\section{REFERENCES}

1. Gibbs, H.K., Ruesch, A.S., Achard, F., Clayton, M.K., Holmgren, P., and Ramankutty, N. (2010). Foley Tropical forests were the primary sources of new agricultural land in the 1980s and 1990s. Proceedings of the National Academy of Sciences of the United States of America 107(38), 1673216737.

2. Foley, J.A., Ramankutty, N., Brauman,K.A., Cassidy, E.S., Gerber, J.S., Johnston, M., Mueller, N. O'Connell, D.C Ray, D. K., West, P. C., Balzer, C. , Bennett, E. M., Carpenter, S. R. Hill, J., Monfreda, C., Polasky, S., Rockström, J., Sheehan, J., Siebert, S., Tilman, D. \& Zaks, D. P. M. (2011). Solutions for a cultivated planet. Nature, 478, 337342.

3. Food and Agriculture Organization. (2010). Global Forest Resources Assessment. Food andAgriculture Organization of the United Nations, Rome. Italy, 340.

4. Pain-Orcet, M., \& Bellefontaine, R. (2004). Trees Outside the Forest:a new perspective on the mana agreement of forest resourcesin the tropics, in Barbin, (ed) Beyond Tropical deforestation UNESCO/CIRAD, Paris, 423-430.

5. Bellefontaine, R., Petit, S., Pain, O., Deleporte, P. \& Bertault, J.G. (2002) Trees outside forests: towards better awareness, Food and Agriculture Organization, Rome, 2016.

6. Forest Survey of India (2019) India State of Forest Report. Dehradun, India.

7. Zomer, R.J., Neufeldt, H., Xu, J., Ahrends, A., \& Bossio, D. (2016). Global Tree Cover and Biomass Carbon on Agricultural Land: The contribution of agroforestry to global and national carbon budgets. Scientific Reports, 6, 29987.

8. Idol, T., Haggar, J., \& Cox, L. (2011). Ecosystem services from smallholder forestry and agroforestry in the tropics. Integrating agriculture, conservation and ecotourism: examples from the field. Springer, 209-270.

9. Herzog, F. (2000). The importance of perennial trees for the balance of northern European agricultural landscapes. Unasylva. 200, 42-48.

10. FAO/FRA. (2000). Global Forest Resources Assessments Food and Agriculture Organization of the United Nations.

11. Pulido, F.J., Díaz, M., \& Hidalgo de Trucios, S.J. (2001). Size structure and regeneration of Spanish holm oak Quercus ilex forests and dehesas: effects of agroforestry use on their long-term sustainability. Forest Ecology and Management, 146(3), 1-13.

12. Foresta Hde, Somarriba E, Temu A, Boulanger, D., \& Feuily H. (2013). Towards the assessment of trees outside forests, Rome, Italy.

13. Plieninger, T., Hartel, T., Martin-López, B., Beaufoy, G., \& Bergmeier, E. (2015). Woodpastures of Europe: Geographic coverage, socialecological values, conservation management, and policy implications. Biological Conservation, 190, 70-79.

14. Solomon, S. (2007). IPCC: Climate changes the physical science basis. In Proceedings of the AGU Fall Meeting Abstracts.

15. Beckschäfer, P., Schnell. S., \& Kleinn, C. (2017). Monitoring and Assessment of Trees Outside Forests (TOF), In: Dagar, J.C. Tewari, V.P. (Eds.), Agroforestry, Springer Singapore: Singapore, 137161.

16. Schnell, S., Altrell, D., Ståhl, G., \& Kleinn, C. (2015). The contribution of trees outside forests to national tree biomass and carbon stocks-a comparative study across three continents. Environmental Monitoring and Assessment, 187(1), 4197. 
17. Food and Agriculture Organization. (2002). Trees outside forests, a key factor in integrated urban and rural management.

18. Sander, H., Polasky, S., \& Haight, R.G. (2010). The value of urban tree cover: A hedonic property price model in Ramsey and Dakota Counties, Minnesota, USA. Ecological Economics, 69(8), 1646-1656.

19. Bremer, L.L., \& Farley, K.A. (2010). Does plantation forestry restore biodiversity or create green deserts? A synthesis of the effects of landuse transitions on plant species richness. Biodiversity and Conservation, 19, 3893-3915.

20. Plieninger, T., Pulido, F.J., \& Schaich, H. (2004). Effects of land use and landscape structure on holm oak recruitment and regeneration at farm level in Quercus ilex L. dehesas. Journal of Arid Environments, 57(3), 345-364.

21. Chave, J.C., Andalo, S., Brown, M.A., Cairns, J.Q. \& Chambers, D. (2005). Tree allometry and improved estimation of carbon stocks and balance in tropical forests. Ecosystem Ecology Oceologia, 145(1), 87-99.

22. Yadav, Y., Chhetri, B.K., Rayamajhi, S., Raj Tiwari, K., \& Kumar, B.P. (2017). Sitaula Importance of Trees Outside Forest (TOF) In Nepal: A Review.

23. Guo, Z.D., Hu, H.F., Pan, Y.D., Birdsey, R.A, Fang, J.Y. (2014). Increasing biomass carbon stocks in trees outside forests in China over the last three decades. Biogeosciences, 11: 4115-4122.

24. Myers, N. (1992). The Primary Source: Tropical Forests and Our Future. Norton, New York.

25. National Population Commission. (2006). Provisional Census Figure. Abuja Nigeria; 1-3.

26. Olofin, E. A. (1987). Some aspects of the physical geography of the Kano region and related human responses. Departmental Lecture Note Series: Geography Department, Bayero University. Debis Standard Printers, Kano, Nigeria. 